\title{
The Impact of Unemployment on Mental and Physical Health, Access to Health Care and Health Risk Behaviors
}

\author{
Jennifer R. Pharr, ${ }^{1}$ Sheniz Moonie, ${ }^{2}$ and Timothy J. Bungum² \\ ${ }^{1}$ School of Community Health Sciences and The Lincy Institute, University of Nevada, Las Vegas (UNLV), P.O. Box 453064, \\ Las Vegas, NV, USA \\ ${ }^{2}$ School of Community Health Sciences, University of Nevada, Las Vegas (UNLV), P.O. Box 453064, Las Vegas, NV, USA
}

Correspondence should be addressed to Jennifer R.Pharr, pharrj@unlv.nevada.edu

Received 29 August 2011; Accepted 18 October 2011

Academic Editors: E. A. Al-Faris, M. F. Allam, and P. Bendtsen

Copyright ( $) 2012$ Jennifer R. Pharr et al. This is an open access article distributed under the Creative Commons Attribution License, which permits unrestricted use, distribution, and reproduction in any medium, provided the original work is properly cited.

\begin{abstract}
The purpose of this study was to examine the impact of employment status and unemployment duration on perceived health, access to health care, and health risk behaviors. Data from Nevada's 2009 Behavioral Risk Factor Surveillance System (BRFSS) were analyzed. We compared participants who were unemployed (greater than and less than one year) to those who were employed and those who were voluntarily out of the labor force (OLF). Unemployed participants had significantly worse perceived mental health profiles, were more likely to delay health care services due to cost, and were less likely to have access to health care than employed participants and OLF participants. OLF participants were not significantly different from employed participants. Contrary to previous findings, unemployed participants in this study were not more likely to binge drink, smoke, or be physically inactive. Findings from this study suggest that the impetus for unemployment, be it voluntary or involuntary, may significantly impact a person's mental health.
\end{abstract}

\section{Introduction}

In 2009, the United States faced its highest unemployment rates since 1982-1983 with rates reaching or exceeding ten percent in the last three months. From January to December 2009 , national unemployment rates increased from $7.7 \%$ to $10.0 \%$ [1]. During this same time period unemployment rates in Nevada increased from $9.6 \%$ to $13.0 \%$, which were the highest in the nation [1].

The relationship between unemployment and poor health has been well documented [2-6]. The unemployed tend to have higher levels of impaired mental health including depression, anxiety, and stress, as well as higher levels of mental health hospital admissions, chronic disease (cardiovascular disease, hypertension, and musculoskeletal disorders), and premature mortality [2, 5-12]. Some longitudinal studies have shown that higher levels of depression and unemployment are not just correlated, but that higher levels of depression are a result of unemployment [11, $13,14]$. Other prospective studies have found that poor mental health contributes to unemployment [15]. A study by Montgomery et al. [11] showed that subjects who had recently become unemployed had an adjusted relative risk of 2.10 for depression and anxiety compared to those who had not recently become unemployed. When participants with preexisting depression were excluded from the study, those who had greater than thirty-seven months of accumulated unemployment were two times more apt to be depressed or anxious than were the employed $(\mathrm{RR}=2.04)$. Additionally, unemployment is associated with unhealthy behaviors such as increased alcohol and tobacco consumption and decreased physical activity $[9,16,17]$. Studies have also demonstrated a positive correlation between employment and better health, improved self-confidence, self-esteem, and happiness $[9,18$, 19].

Jahoda has argued that being employed satisfies a psychological need, a need which must be filled to maintain good mental health $[20,21]$. Because of this psychological need which is fulfilled by employment, not only are the unemployed at risk for mental health problems, but also 
are people who are out of the labor force (OLF). People who are OLF do not have a paid job and they are not seeking employment. The OLF category includes students, homemakers, and retirees [5].

Previous research has established employment status (employed or unemployed) as a determinant of health [26]. However, few studies have segmented the "unemployed" as (1) those who did not have work and were seeking employment - unemployed, and (2) those who did not have work and were not seeking employment-OLF. The purpose of this study was to compare perceived mental and physical health, access to health care, and risky health behaviors based on employment status (employed, unemployed, and OLF) and duration of unemployment (less than one year, greater than one year) by utilizing 2009 Behavioral Risk Factor Surveillance System (BRFSS) data. The research questions addressed by this study were as follows (1) Are general, mental, and physical health responses different based on employment status (employed, unemployed less than one year, unemployed longer than one year, or OLF)? (2) Do smoking, drinking, and physical inactivity rates differ by employment status? (3) Does access to health care or a delay in seeking health care services due to cost differ based on employment status? Based on Jahoda's theory, we hypothesized that the employed would have better perceived mental and physical health than the OLF participants and the unemployed participants regardless of length of unemployment.

\section{Methods}

2.1. Study Design and Data Collection. This study was a secondary analysis of the 2009 Nevada BRFSS survey data. Valuable mental health data is gathered through the administration of the BRFSS. The BRFSS is an annual, national, cross-sectional, random-digit dialing telephone survey that is conducted among noninstitutionalized adults 18 years of age or older in the United States [22]. The survey is a collaborative effort between the states and the Centers for Disease Control and Prevention. Survey questions gather information regarding demographics (age, gender, employment status, income level, education completed, etc.), perceived health status (general health, physical health, and mental health), and chronic disease status and health behaviors (smoking, drinking, physical activity, etc.). The survey includes a core component with questions that are asked to all participants in every state. Core component questions include demographic information and current behaviors that impact health. Time to complete the core component questions is approximately fifteen minutes. Additionally, there are optional modules which the states may elect to fund if there is a special interest. In 2009, BRFSS participants from eight states were asked the optional mental illness questions in addition to the core component items. These states included Georgia, Hawaii, Mississippi, Missouri, Nevada, South Carolina, Vermont, and Wyoming [22]. We used Nevada for this study because the high rate of unemployment ensured that we had a sufficient sample size (n) for the unemployment groups [1].
To provide an adequate sample size for smaller demographic areas in Nevada, disproportionate stratified sampling was employed. Smaller geographically defined populations in Nevada were oversampled to provide more precise estimates for those populations. Disproportionate sampling is preferred to proportionate sampling in states where the population is concentrated in a small geographical area as in Nevada. Data were collected regarding demographics, perceived general, physical, and mental health, chronic disease presence, and health behaviors. After the data were collected, they were then weighted for population attributes and nonresponse [22]. In 2009, 3,840 adult Nevadans completed the BRFSS survey. The response rate was $50.71 \%$. Perceived health status was assessed by one question: would you say that in general your health is excellent, very good, good, fair, or poor? The question that measured perceived physical health was: for how many days during the past thirty days was your physical health not good? Two strategies were employed to assess perceived mental health: (1) a single question addressed the number of recent days of poor mental health: for how many days during the past thirty days was your mental health not good? and (2) A series of items targeting mental illness. The mental illness questions utilized a Likert scale with 1 (all the time) to 5 (none of the time) as anchors. These items measured the frequency of feelings of nervousness, hopelessness, restlessness/fidgety, depression, increased effort, and worthlessness. Lower scores represented poorer perceived health.

2.2. Statistical Analysis. SAS 9.2 was used for the statistical analyses. Weighted descriptive statistics were performed to describe the characteristics of the population by gender, age, race, education, and income using PROC SURVEYFREQ. The Rao-Scott Chi-square test was utilized to determine statistically significant differences in proportions of employed, unemployed less than one year, unemployed longer than one year, and OLF with regard to descriptive statistics. Multiple logistic regression (MLR) was used to analyze dichotomous (yes/no) dependent variables using PROC SURVEYLOGISTIC. Employed participants served as the reference group. The MLR was then repeated while adjusting for age, income, education, and gender. An analysis of variance (ANOVA) and an analysis of covariance (ANCOVA) were conducted using PROC SURVEYREG to determine if the mean number of days of poor physical health or poor mental health or if mean mental health question scores varied between people who were employed, unemployed less than one year, unemployed longer than one year, and OLF. Age, income, gender, and education were used as covariates in the ANCOVA. A Tukey post hoc test was utilized when overall ANOVA/ANCOVA results were significant for group differences.

\section{Results}

Descriptive statistics of the sample are provided in Table 1 by employment status. Each variable showed significant differences between the groups. A higher proportion of employed and unemployed less than one year participants 
TABle 1: Descriptive statistics by employment status.

\begin{tabular}{|c|c|c|c|c|c|}
\hline \multirow[t]{2}{*}{ Variable } & Employed & $\begin{array}{c}\text { Unemployed } \\
>1 \text { year }\end{array}$ & $\begin{array}{l}\text { Unemployed } \\
<1 \text { year }\end{array}$ & $\begin{array}{l}\text { Out of labor } \\
\text { force }\end{array}$ & \multirow[b]{2}{*}{$P$-value** } \\
\hline & $\begin{array}{l}\text { Weighted \% } \\
(n=1086)\end{array}$ & $\begin{array}{l}\text { Weighted \% } \\
\quad(n=142)\end{array}$ & $\begin{array}{c}\text { Weighted \% } \\
\quad(n=209)\end{array}$ & $\begin{array}{c}\text { Weighted \% } \\
(n=1434)\end{array}$ & \\
\hline Gender & & & & & $<0.001^{*}$ \\
\hline Male & 55.7 & 49.48 & 60.15 & 35.81 & \\
\hline Female & 44.3 & 50.52 & 39.85 & 64.19 & \\
\hline Age & & & & & $<0.001^{*}$ \\
\hline $18-24$ & 7.01 & 6.29 & 13.18 & 7.14 & \\
\hline $25-49$ & 63.28 & 66.29 & 66.54 & 21.86 & \\
\hline$>50$ & 29.68 & 27.42 & 20.27 & 70.99 & \\
\hline Race & & & & & $<0.001^{*}$ \\
\hline White & 72.99 & 55.71 & 52.06 & 80.11 & \\
\hline Black & 4.06 & 5.27 & 7.25 & 4.5 & \\
\hline Hispanic & 14.08 & 21.01 & 29.32 & 10.39 & \\
\hline Other & 8.95 & 18 & 11.36 & 4.99 & \\
\hline Income & & & & & $<0.001^{*}$ \\
\hline$<\$ 20.000$ & 5.29 & 34.70 & 33.86 & 15.47 & \\
\hline$\$ 20 \mathrm{~K}$ to $<\$ 50 \mathrm{~K}$ & 26.77 & 47.79 & 39.44 & 45.27 & \\
\hline$>\$ 50 \mathrm{~K}$ & 67.93 & 17.5 & 26.7 & 39.26 & \\
\hline Education & & & & & $<0.001^{*}$ \\
\hline$<$ High School Grad & 4.54 & 7.15 & 16.23 & 9.04 & \\
\hline High School Grad & 25.62 & 33.74 & 38.96 & 31.29 & \\
\hline Some College & 69.84 & 59.11 & 44.8 & 59.67 & \\
\hline
\end{tabular}

${ }^{*}$ Significant $(P<0.05),{ }^{* *}$ Rao Scott $\chi^{2}$.

were male while a higher proportion of unemployed longer than one year and OLF participants were female $(P<0.001)$. The majority of OLF participants were in the fifties and older age bracket, while a majority of the employed and unemployed participants were in the $24-49$ year age bracket $(P<0.001)$. Employed and OLF participants were more likely to be white as compared with unemployed participants. Employed and OLF participants were less likely to indicate that they were Hispanic, Black, or other ethnicity compared to unemployed participants $(P<0.001)$. Employed participants were more likely to be in the highest income bracket ( $>$ \$50.000), while unemployed and OLF participants were more likely to be in the middle income bracket $(\$ 20.000$ $\$ 50.000)(P<0.001)$. Employed participants had the highest proportion of participants with some college education $(P<$ $0.001)$.

3.1. Access to Health Care. Crude and adjusted (age, income, gender, and race) odds ratios (OR) with a $95 \%$ confidence interval (CI) are presented in Table 2. Final adjusted models which controlled for demographic variables, indicated that employed participants were at least 4.1 times more likely to have access to health care than were unemployed participants. Unemployed participants were at least 2.1 times more likely to delay health care due to cost as compared with employed participants. There was no significant difference in access to health care or delaying health care due to cost when employed participants were compared to OLF participants.

3.2. Health Risk Behaviors. Crude and adjusted odds ratios for health risk behaviors are presented in Table 2. Crude odds ratios for smoking demonstrated that unemployed participants were more likely to smoke and OLF participants were less likely to smoke compared to employed participants. After adjustments, the lone significant result was that OLF participants were 40 percent (95\% CI 0.38-0.93) less likely to smoke than were employed participants. There was no significant difference between employed and unemployed regarding binge drinking (defined as five or more drinks for a male or four or more drinks for a female on one occasion in the past thirty days). The crude odds ratio showed that OLF participants were fifty-six percent (95\% CI 0.29-0.67) less likely to binge drink than employed participants; however, this result did not retain significance after adjustment. Crude odds ratios showed that unemployed and OLF participants were more likely to rate their general health as poor/fair; however, these results attenuated after adjusting for age, income, gender, race, and education.

3.3. Perceived Mental Health. ANOVA and ANCOVA models for nervousness, hopelessness, restlessness, depression, increased effort, worthlessness, number of days of poor 
TABLE 2: Multiple logistic regression: crude and adjusted odds ratios: Nevada 2009 BRFSS.

\begin{tabular}{|c|c|c|c|c|c|c|}
\hline \multirow[t]{2}{*}{ Variables } & \multicolumn{2}{|c|}{ Unemployed $<$ one year } & \multicolumn{2}{|c|}{ Unemployed $>$ one year } & \multicolumn{2}{|c|}{ Out of labor force } \\
\hline & OR & $95 \% \mathrm{CI}$ & OR & $95 \% \mathrm{CI}$ & OR & $95 \% \mathrm{CI}$ \\
\hline \multicolumn{7}{|c|}{ No Access to Health Care } \\
\hline Crude & $8.1^{*}$ & $4.77-13.76$ & $9.34^{*}$ & $5.09-17.17$ & 0.87 & $0.56-1.34$ \\
\hline Adjusted & $4.05^{*}$ & $2.32-7.05$ & $4.73^{*}$ & $2.27-9.83$ & 0.9 & $0.52-1.56$ \\
\hline \multicolumn{7}{|c|}{ Delaying Health Care due to Cost } \\
\hline Crude & $3.71^{*}$ & $2.14-6.44$ & $4.88^{*}$ & $2.57-9.26$ & 0.86 & $0.55-1.34$ \\
\hline Adjusted & $2.1^{*}$ & $1.11-3.98$ & $2.42 *$ & $1.14-5.15$ & 0.84 & $0.50-1.56$ \\
\hline \multicolumn{7}{|l|}{ Smoker } \\
\hline Crude & $2.44^{*}$ & $1.24-4.82$ & $3.04^{*}$ & $1.42-6.52$ & $0.57^{*}$ & $0.40-0.80$ \\
\hline Adjusted & 1.83 & $0.82-4.05$ & 1.78 & $0.75-4.26$ & $0.6^{*}$ & $0.38-0.93$ \\
\hline \multicolumn{7}{|c|}{ Binge Drinker } \\
\hline Crude & 1.32 & $0.62-2.8$ & 0.64 & $0.26-1.60$ & $0.44^{*}$ & $0.29-0.67$ \\
\hline Adjusted & 1.47 & $0.66-3.28$ & 0.49 & $0.16-1.40$ & 0.73 & $0.46-1.19$ \\
\hline \multicolumn{7}{|c|}{ Physically Inactive } \\
\hline Crude & 1.18 & $0.67-2.06$ & 1.15 & $0.59-2.22$ & 1.2 & $0.91-1.57$ \\
\hline Adjusted & 0.77 & $0.35-1.71$ & 0.83 & $0.39-1.74$ & 0.83 & $0.61-1.13$ \\
\hline \multicolumn{7}{|c|}{ Poor/Fair General Health } \\
\hline Crude & $2.15^{*}$ & $1.04-4.42$ & $2.82 *$ & $1.33-5.96$ & $2.25^{*}$ & $1.62-3.14$ \\
\hline Adjusted & 1.13 & $0.51-2.53$ & 1.71 & $0.70-4.15$ & 1.4 & $1.0-2.06$ \\
\hline
\end{tabular}

${ }^{*}$ Significant $(P<0.05)$, Reference group: Employed.

physical, and mental health were all significant $(P<0.001)$. ANOVA results were further analyzed using a Tukey post hoc test (Table 3). Participants who were unemployed less than one year were significantly more likely to have lower (worse) perceived mental health scores than were employed and OLF participants and to report a significantly higher number of days of poor mental health. Participants who were unemployed longer than one year had significantly lower (worse) mental health scores compared to the employed and OLF participants and reported more days of poor physical and mental health.

ANCOVA results were further analyzed using a Tukey post hoc test (Table 3). No significant differences were found when comparing employed and OLF participants to participants who had been unemployed less than one year. Significant differences remained between employed participants and participants who had been unemployed longer than one year with the unemployed having significantly lower (worse) perceived mental health scores for nervousness $(P=0.009)$, hopelessness $(P \leq 0.001)$, depression $(P=0.05)$, increased effort $(P=0.007)$, and worthlessness $(P=0.005)$. The unemployed also reported significantly more days of poor physical health $(P=0.02)$ and poor mental health $(P=$ $0.02)$. Significant differences also remained between the OLF participants and participants who had been unemployed longer than one year with the unemployed having significantly lower scores for nervousness $(P \leq 0.00)$, hopelessness $(P \leq 0.001)$, depression $(P=0.05)$, increased effort $(P=$ $0.004)$, and worthlessness $(P=0.002)$. The unemployed reported significantly more days of poor physical health $(P=$ $0.01)$ and poor mental health $(P=0.009)$.

\section{Discussion}

The most interesting finding of this study is that all the unemployed, with either less or greater than one year of unemployment, reported significantly worse perceived mental health scores as compared to employed or OLF participants. However, when age, income, gender, and education were used as covariates, only those unemployed for greater than one year had significantly worse scores. This finding is supportive of work that suggests that there is a relationship between one's work status and mental health and implies that people attach at least some of their self-worth to being productive, working members of society $[2,4,5,13,14]$. It is of note that those who were unemployed, but not looking for work (OLF), had more favorable mental health scores than did those who were involuntarily unemployed. It is likely that many of the people in the OLF group had voluntarily retired as $71 \%$ were older than 50 years. It also appears that members of the OLF group may be better off financially than the involuntarily unemployed as a much smaller proportion of this group were assigned to the lowest income group (see Table 1). It is also possible that because unemployment is a planned and expected event for those who choose to retire, rather than an undesired, disruptive event, and beyond the control of the involuntarily unemployed, differences in mental health status between these groups are seen. These factors likely explain why our findings do not agree with those of Jahoda or Paul et al, who found that the employed tend to have better mental health profiles than all unemployed groups, regardless of the impetus for being unemployed, be it voluntary or involuntary $[5,20,21]$. 
TABLE 3: ANOVA and ANCOVA Tukey post hoc test: Nevada 2009 BRFSS.

\begin{tabular}{|c|c|c|c|c|c|}
\hline & $\begin{array}{l}\text { Unemployed }<1 \\
\text { year** }\end{array}$ & $\begin{array}{c}\text { Unemployed }>1 \\
\text { year** }\end{array}$ & $\begin{array}{c}\text { Unemployed }<1 \\
\text { year*** }\end{array}$ & $\begin{array}{c}\text { Unemployed }>1 \\
\text { year*** }\end{array}$ & $\begin{array}{c}\text { Out of Labor } \\
\text { Force }^{* *}\end{array}$ \\
\hline Models & Adj. $P$ & Adj. $P$ & Adj. $P$ & Adj. $P$ & Adj. $P$ \\
\hline \multicolumn{6}{|l|}{ Nervous } \\
\hline ANOVA & $0.03^{*}$ & $<0.001^{*}$ & $0.02^{*}$ & $<0.001^{*}$ & 0.95 \\
\hline ANCOVA & 0.47 & $0.009^{*}$ & 0.18 & $<0.001^{*}$ & 0.62 \\
\hline \multicolumn{6}{|l|}{ Hopeless } \\
\hline ANOVA & $<0.001^{*}$ & $<0.001^{*}$ & $<0.001^{*}$ & $<0.001^{*}$ & 0.53 \\
\hline ANCOVA & 0.1 & $<0.001^{*}$ & 0.07 & $<0.001^{*}$ & 0.93 \\
\hline \multicolumn{6}{|l|}{ Restless } \\
\hline ANOVA & 0.43 & $0.009^{*}$ & $0.01^{*}$ & $<0.001^{*}$ & $0.01^{*}$ \\
\hline ANCOVA & 0.97 & 0.22 & 0.37 & 0.09 & 0.79 \\
\hline \multicolumn{6}{|l|}{ Depressed } \\
\hline ANOVA & $0.004^{*}$ & $0.002^{*}$ & 0.07 & $0.007^{*}$ & 0.16 \\
\hline ANCOVA & 0.22 & $0.05^{*}$ & 0.16 & $0.05^{*}$ & 0.93 \\
\hline \multicolumn{6}{|c|}{ Increased Effort } \\
\hline ANOVA & $0.006^{*}$ & $<0.001^{*}$ & $0.003^{*}$ & $<0.001^{*}$ & 0.95 \\
\hline ANCOVA & 0.34 & $0.007^{*}$ & 0.43 & $0.004^{*}$ & 0.35 \\
\hline \multicolumn{6}{|l|}{ Worthless } \\
\hline ANOVA & $<0.001^{*}$ & $<0.001^{*}$ & $0.04^{*}$ & $<0.001^{*}$ & $0.01^{*}$ \\
\hline ANCOVA & 0.24 & $0.005^{*}$ & 0.41 & $0.002 *$ & 0.94 \\
\hline \multicolumn{6}{|c|}{$\begin{array}{l}\text { \# days of Poor } \\
\text { Physical Health }\end{array}$} \\
\hline ANOVA & 0.74 & $0.01^{*}$ & 0.11 & 0.32 & $0.01^{*}$ \\
\hline ANCOVA & 1 & $0.02 *$ & 0.94 & $0.01^{*}$ & 0.74 \\
\hline \multicolumn{6}{|l|}{$\begin{array}{l}\text { \# days of Poor } \\
\text { Mental Health }\end{array}$} \\
\hline ANOVA & $0.01^{*}$ & $<0.001^{*}$ & $<0.001^{*}$ & $<0.001^{*}$ & 0.27 \\
\hline ANCOVA & 0.59 & $0.02 *$ & 0.06 & $0.009^{*}$ & $0.04^{*}$ \\
\hline
\end{tabular}

* Significant $(P<0.05)$.

$* *$ Compared to Employed, $* * *$ Compared to OLF.

The lack of control that the involuntarily unemployed may feel is supportive of a model developed by Karasek and Theorell [23]. Their model posits that unemployed people have lower control over their "work" environment and reduced demand placed on them as compared to the employed. An aspect of the demand-control model is that having a reasonable amount of "demand" placed on a person improves health, while having an excessively high or a low amount of demand can be detrimental to a person's health. This finding is also supportive of the work of Poortinga, Dunstan, and Fune, who have shown that lack of control affects health [24].

The data in Table 3 suggest that duration of unemployment is also a factor in determining the severity of effects of being jobless. These findings are plausible and are consistent with those of Montgomery et al. [11]. A deprivation model contends that as unemployment persists, economic resources dwindle and that less money, either "directly or indirectly, worsens the prerequisites for good health" [25]. This is relevant in America because unemployment benefits expire after the ninety-ninth week of idleness.
Unemployed participants, both those out of work for less, and longer, than one year, were over four times more likely to lack health care coverage and over two times more likely to report delaying health care services due to cost compared to employed participants after adjusting for age, income, gender, race, and education. This lack of health care for the unemployed exists in spite of a federal program, COBRA, that was designed to provide health care insurance to the unemployed [26]. Although these findings are not surprising, they are of concern considering that unemployed participants were more likely to report poorer perceived mental health and, therefore, are more likely to need mental health services [11]. People who experience involuntary unemployment or whose unemployment persists may be a targeted group which needed preventive mental health services.

Although most of our results identified negative associations of unemployment and health, that relationship was not universal. We found that unemployed participants were no more likely to engage in binge drinking and were not less likely to participate in physical activity than employed 
participants. This finding is inconsistent with previous studies that showed higher rates of alcohol consumption and binge drinking among the unemployed [9, 17, 27, 28]. Unemployed participants were significantly more likely to report smoking and poor/fair health compared to employed participants, but the statistical significance did not persist when adjustments for age, income, gender, race, and education were made. Our findings also fail to support earlier work that showed more smoking and decreased physical activity among the unemployed [16, 17, 29]. Fagan et al. found that unemployed people were more likely to smoke than employed people [29]. However, they also found that people who had been unemployed for greater than six months were more likely to successfully stop smoking than people who had been unemployed for less than six months. Findings from this study and Fagan et al. may suggest that the lower incomes of unemployed and OLF people may play a role in attenuating these behaviors [29]. In general, smoking and alcohol consumption decrease when the economy is in decline, when unemployment rates increase, and people have less discretionary money [27].

4.1. Limitations of This Study. There were limitations with this study. The BRFSS is a cross-sectional survey and therefore causation cannot be determined. Because we cannot be certain of the temporal sequence of unemployment and mental health in this study, we must consider the possibility that those with poor mental health may be more likely to be unemployed, rather than those who are unemployed having poorer mental health [15]. There was also a possibility of bias resulting from self-reported information. The participants may have over- or underreported information if they perceived it to be a socially desirable response [30]. The BRFSS is a household telephone survey and cellular phones were not included as part of the regular BRFSS sample in 2009 [22]. People without a home telephone or those who exclusively use a cell phone were excluded from the survey. There was no direct method for correcting for those who do not have a home telephone and this may have resulted in an underestimation of the true prevalence of employment or unemployment in this group [22].

\section{Conclusion}

In 2009, unemployment rates reached their highest level since the early 1980s in the United States. During that year, people who reported being unemployed greater than one year also had significantly worse perceived mental health scores, while all unemployed were less likely to have access to health care coverage and were more likely to delay medical treatment due to cost when compared to employed people or people who were voluntarily out of the labor force. Among the group studied, mental health scores seemed to be impacted by the source of the unemployment, voluntary versus involuntary, with those who were voluntarily unemployed having mental health scores similar to those who were employed. This study highlights the need for more research to fully understand the impact of unemployment, be it voluntary or involuntary, on mental health.

\section{References}

[1] United States Department of Labor. 2011. Bureau of Labor Statistics. Labor Force Statistics from the Currently Population Survey, http://data.bls.gov/pdq/SurveyOutputServlet? data_tool=latest_numbers\&series_id=LNS14000000.

[2] J. A. Dean and K. Wilson, "“Education? It is irrelevant to my job now. It makes me very depressed": exploring the health impacts of under/unemployment among highly skilled recent immigrants in Canada," Ethnicity and Health, vol. 14, no. 2, pp. 185-204, 2009.

[3] M. Marmot and R. Wilkinson, Social Determinants of Health, Oxford University Press, London, UK, 2nd edition, 2006.

[4] F. M. McKee-Ryan, Z. Song, C. R. Wanberg, and A. J. Kinicki, "Psychological and physical well-being during unemployment: a meta-analytic study," Journal of Applied Psychology, vol. 90, no. 1, pp. 53-76, 2005.

[5] K. I. Paul, E. Geithner, and K. Moser, "Latent deprivation among people who are employed, unemployed, or out of the labor force," Journal of Psychology, vol. 143, no. 5, pp. 477-491, 2009.

[6] S. H. Wilson and G. M. Walker, "Unemployment and health: a review," Public Health, vol. 107, no. 3, pp. 153-162, 1993.

[7] S. Arber and E. LaHelma, "Inequalities in women's and men's ill-health: Britain and Finland compared," Social Science and Medicine, vol. 37, no. 8, pp. 1055-1068, 1993.

[8] M. Bartley, "Unemployment and ill health: understanding the relationship," Journal of Epidemiology and Community Health, vol. 48, no. 4, pp. 333-337, 1994.

[9] D. Dooley, R. Catalano, and R. Hough, "Unemployment and alcohol disorder in 1910 and 1990: drift versus social causation," Journal of Occupational and Organizational Psychology, vol. 65, pp. 277-290, 1992.

[10] A. Hammarström, "Health consequences of youth unemployment-review from a gender perspective," Social Science and Medicine, vol. 38, no. 5, pp. 699-709, 1994.

[11] S. M. Montgomery, D. G. Cook, M. J. Bartley, and M. E. J. Wadsworth, "Unemployment pre-dates symptoms of depression and anxiety resulting in medical consultation in young men," International Journal of Epidemiology, vol. 28, no. 1, pp. 95-100, 1999.

[12] P. O'Campo, W. W. Eaton, and C. Muntaner, "Labor market experience, work organization, gender inequalities and health status: results from a prospective analysis of US employed women," Social Science and Medicine, vol. 58, no. 3, pp. 585594, 2004.

[13] W. Bolton and K. Oatley, "The longitudinal study of social support and depression in unemployed men," Psychological Medicine, vol. 17, no. 2, pp. 453-460, 1987.

[14] M. Frese and G. Mohr, "Prolonged unemployment and depression in older workers: a longitudinal study of intervening variables," Social Science and Medicine, vol. 25, no. 2, pp. 173-178, 1987.

[15] P. Butterworth, L. Leach, J. Pirkis, and M. Kelaher, "Poor mental health influences risk and duration of unemployment: a prospective study," Social Psychiatry and Psychiatric Epidemiology. In press.

[16] J. P. Grayson, "Health, physical activity level, and employment status in Canada," International Journal of Health Services, vol. 23, no. 4, pp. 743-761, 1993. 
[17] A. J. Lee, I. K. Crombie, W. C. S. Smith, and H. D. TunstallPedoe, "Cigarette smoking and employment status," Social Science and Medicine, vol. 33, no. 11, pp. 1309-1312, 1991.

[18] L. Cai and G. Kalb, "Health status and labour force participation: evidence from Australia," Health Economics, vol. 15, no. 3, pp. 241-261, 2006.

[19] C. E. Ross and J. Mirowsky, "Does employment affect health?" Journal of Health and Social Behavior, vol. 36, no. 3, pp. 230 243, 1995.

[20] M. Jahoda, Employment and Unemployment: A SocialPsychological Analysis, Cambridge University Press, England, UK, 1982.

[21] M. Jahoda, "Social institutions and human needs: a comment on Fryer and Payne," Leisure Studies, vol. 3, pp. 297-299, 1984.

[22] Center for Disease Control and Prevention. Overview: BRFSS, http://www.cdc.gov/brfss/technical_infodata/surveydata/2009 .htm.

[23] R. Karasek and T. Theorell, Healthy Work: Stress, Productivity, and Reconstruction of Working Life, Basic Books, New York, NY, USA, 1990.

[24] W. Poortinga, F. D. Dunstan, and D. L. Fone, "Health locus of control beliefs and socio-economic differences in self-rated health," Preventive Medicine, vol. 46, no. 4, pp. 374-380, 2008.

[25] U. Janlert and A. Hammarstrom, "Which theory is best? Explanatory models of the relationship between unemployment and health," BMC Public Health, vol. 9, article 235, pp. 235-243, 2009.

[26] K. Linehan, "Keeping Health Insurance After Job Loss: "COBRA Continuation Coverage and Subsidies. National Health Policy Forum"', 2011, http://www.nhpf.org/library/ issue-briefs/IB837_COBRA_06-24-10.pdf.

[27] D. Henkel, "Unemployment and substance use: a review of the Literature (1990-2010)," Current Drug Abuse Reviews, vol. 4, no. 1, pp. 4-27, 2011.

[28] D. Dooley, J. Fielding, and L. Levi, "Health and unemployment," Annual Review of Public Health, vol. 17, pp. 449-465, 1996.

[29] P. Fagan, V. Shavers, D. Lawrence, J. T. Gibson, and P. Ponder, "Cigarette smoking and quitting behaviors among unemployed adults in the United States," Nicotine and Tobacco Research, vol. 9, no. 2, pp. 241-248, 2007.

[30] A. S. Adams, S. B. Soumerai, J. Lomas, and D. RossDegnan, "Evidence of self-report bias in assessing adherence to guidelines," International Journal for Quality in Health Care, vol. 11, no. 3, pp. 187-192, 1999. 


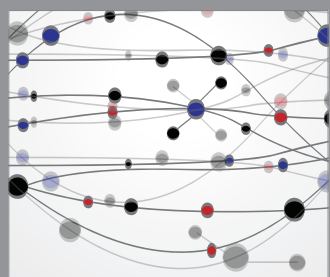

The Scientific World Journal
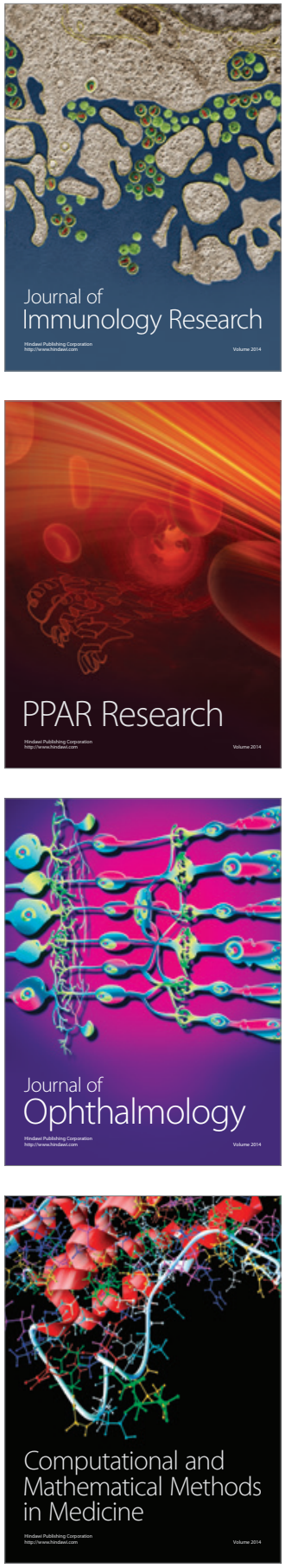

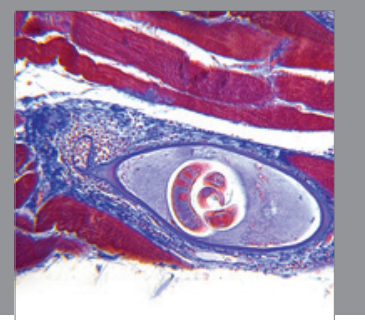

Gastroenterology

Research and Practice
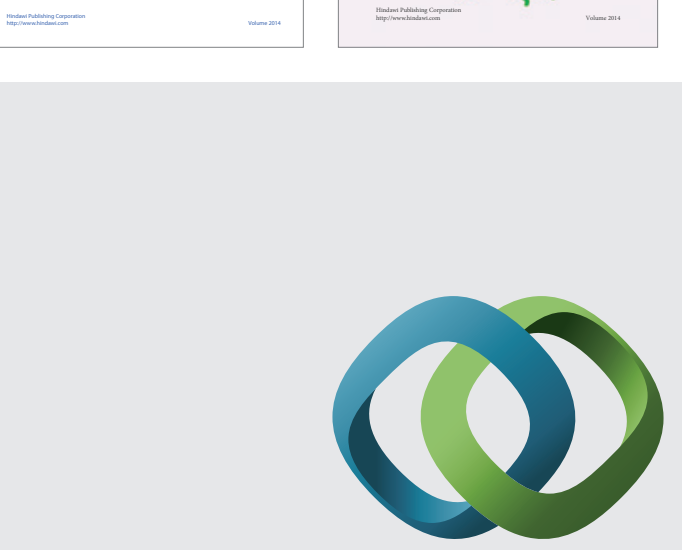

\section{Hindawi}

Submit your manuscripts at

http://www.hindawi.com
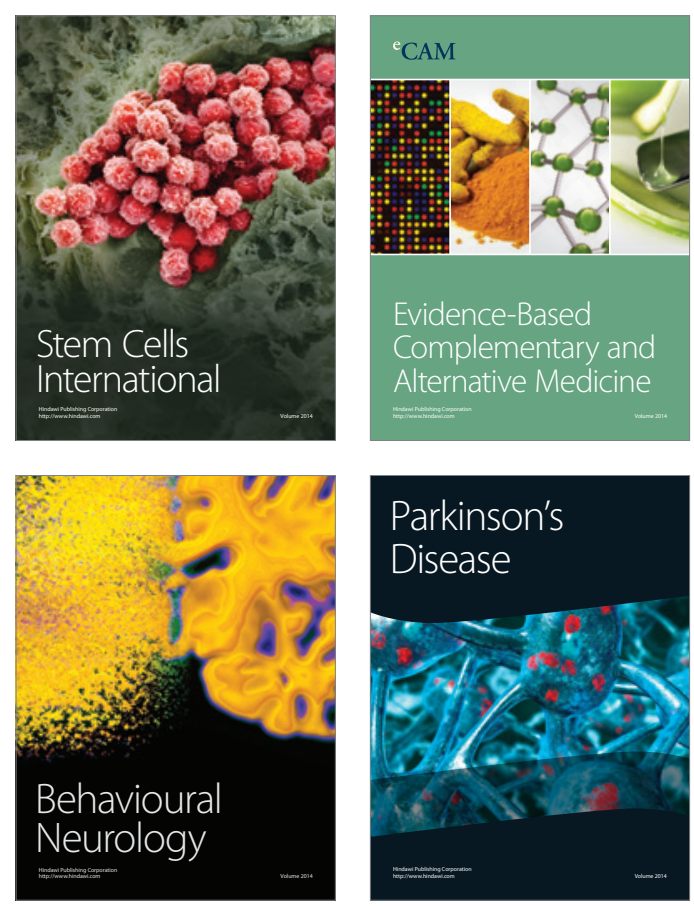

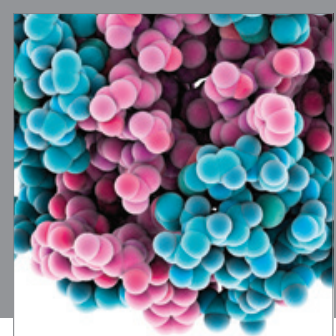

Journal of
Diabetes Research

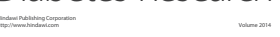

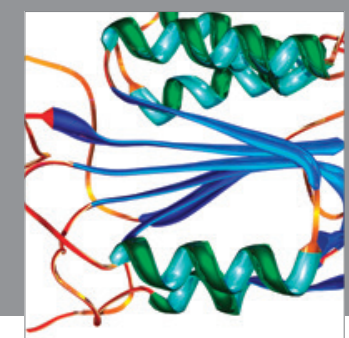

Disease Markers
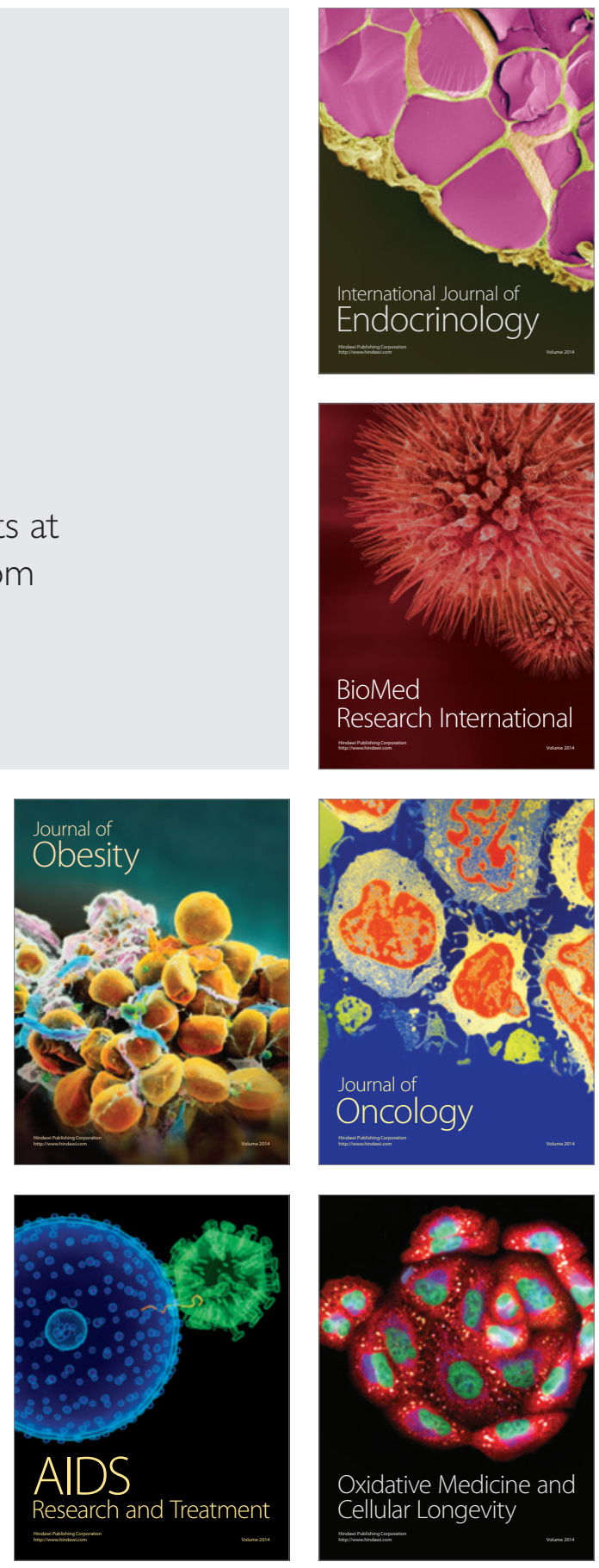